\title{
Tracheostomy Ventilation in a Patient with Amyotrophic Lateral Sclero
}

\author{
Muhammad K Rafiq* \\ Registrar in Neurology, Sheffield Teaching Hospitals NHS Trust, UK
}

Submission: February 9, 2018; Published: August 28, 2018

*Corresponding author: Muhammad K Rafiq, Registrar in Neurology, Sheffield Teaching Hospitals NHS Trust, UK, Email: m.k.rafiq@sheffield.ac.uk

Keywords: Tracheostomy;Neurological;Ventilation

Abbreviations: ALS:Amyotrophic lateral sclerosis;NIV:non-invasive ventilation;TV:tracheostomy ventilation

\section{Editorial}

Amyotrophic lateral sclerosis (ALS) is a rapidly progressive terminal neurological disorder. It causes profound disability and average life span is 2-3 years from symptom onset. Death is usually due to respiratory failure. ALS can affect adults of any age, but the mean age of onset is 55-60 years. There is no cure and treatment is only supportive. Of supportive interventions, supporting respiratory function with non-invasive ventilation (NIV) has been demonstrated to have the largest survival benefit[1]. Due to the relentless degeneration of the motor neurones innervating the respiratory muscles, after a period of successful benefit, NIV becomes ineffective and the patient can only survive if provided with invasive ventilation i.e., tracheostomy ventilation (TV).

There are illustrious cases such as that of Prof. Stephen Hawking where life expectancy was significantly prolonged with TV and good quality nursing care. TV, however requires extensive resources and 24 hour nursing care. It is also associated with complications such as stoma infection, aspiration, fistula formation etc. There are also ethical issues as to prolong life in the face of a progressive and disabling illness may cause a patient being trapped in his body and quality of life may not be sustained. Also, once initiated the decision to stop ventilator can be emotionally challenging for the patient as well as the physician, as it can be seen as a form of euthanasia. For these reasons TV is not actively offered to the patients with ALS in Europe. In the United States, most insurance policies do not cover the cost of TV, however, in Japan cost of TV is fully covered by the government and medical insurance. According to a survey only $30 \%$ of the patients took this option with informed choice[2]. Another survey reported that only $8 \%$ of ALS specialists discussed this option with their patient[3].
Studies on quality of life after tracheostomy have reported that patients were satisfied with their decision to have a tracheostomy and their quality of life was acceptable[4,5]. Benefits of TV, however, have not been confirmed in a randomised controlled trial. Despite the lack of level 1 evidence but support from prospective studies, I feel that the option of TV as a life prolonging measure should be available to some carefully selected patients with ALS, for examples patients who have specific aims or reasons to live for. I illustrate this argument with the following case.

Mr. X was an active researcher when diagnosed with ALS at the age of 55 years. He was initially supported with NIV, which gradually became ineffective. He discussed the option of having a tracheostomy with his neurologist. He expressed a specific desire to finish his scientific papers and to spend some time with his family. He said "As long as I can continue to use my brain to communicate, life is worth living". He also expressed a desire to have control over stopping ventilation when he feels that the burden of disease was too much for him and his family. With the help of his neurologist, he wrote an advanced directive clearly outlining the circumstances when he would wish TV to be withdrawn. He underwent tracheostomy and was discharged home with 24 hour nursing care. He coped well for about a year following which he became almost bed bound and concentration span of reading and writing on computer became less. Another 6 months later he expressed that he had enough and was prepared to stop the ventilation. As per his advanced directive palliative care was initiated and his ventilator was stopped while he was kept sedated with midazolam. His respiration ceased 15 minutes post withdrawal. His family felt the transition was peaceful.

This case illustrates that in carefully selected patients TV can be used to accomplish specific goals which may be 
important for patients and their families. However, there are two ethical arguments against this approach. An important principle of medical ethics is "equality of access" i.e., access to medical interventions should be same for all patients and patients are not discriminated on the grounds of age and social class or productivity. In other words, if we were to offer TV to the patients with ALS, it should be offered to all without discrimination. Secondly, health care resources are finite and interventions need to fulfil the criteria of cost effectiveness and health economics. TV may not be considered as cost effective if assessed in an unselected cohort of ALS patients. It will also be unethical to inform patients of an intervention which has high financial burden and the cost cannot be covered in the national health services. Hence, realistically speaking, TV is an option for only those patients who could fund its cost by their own means. Where appropriate TV should be carefully planned with detailed discussion and decisions/goals documented in an advanced directive.

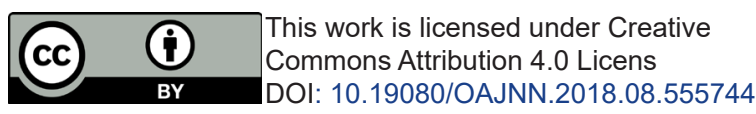

\section{References}

1. Bourke SC, Tomlinson M, Williams TL, Bullock RE, Shaw PJ, et al (2006) Effects of non-invasive ventilation on survival and quality of life in patients with amyotrophic lateral sclerosis: a randomised controlled trial. Lancet Neurol 5(2): 140-147.

2. Yanagisawa NSM, Momoi H, Tanabe H, Mizuno Y, Takahashi K (1996) Nationwide study on the natural course of amyotrophic lateral sclerosis in janpan. Annual report of the research committee of CNS Degeneration Diseases, Ministry of Health and Welfare in Japan for the year pp. 253-255.

3. O’Neill CL1, Williams TL, Peel ET, McDermott CJ, Shaw PJ, et al. (2012) Non-invasive ventilation in motor neuron disease: an update of current UK practice. J Neurol Neurosurg Psychiatry 83(4): 371-376.

4. Cazzolli PA, Oppenheimer EA (1996) Home mechanical ventilation for amyotrophic lateral sclerosis: nasal compared to tracheostomyintermittent positive pressure ventilation. J Neurol Sci 139: 123-128.

5. Sancho J, Servera E, Díaz JL, Bañuls P, Marín J (2011) Home tracheotomy mechanical ventilation in patients with amyotrophic lateral sclerosis: causes, complications and 1-year survival. Thorax 66(11): 948-952.

\section{Your next submission with Juniper Publishers will reach you the below assets}

- Quality Editorial service

- Swift Peer Review

- Reprints availability

- E-prints Service

- Manuscript Podcast for convenient understanding

- Global attainment for your research

- Manuscript accessibility in different formats

( Pdf, E-pub, Full Text, Audio)

- Unceasing customer service

Track the below URL for one-step submission https://juniperpublishers.com/online-submission.php 